\title{
Roles of Community-Based Seed System to Mitigate Seed Shortage Problem Under Metekel Zone, Western Ethiopia
}

\author{
Takele Atnafu Delele*, Dirshaye Hailu Gebre, Talefe Ayele Zenebe \\ Department of Agricultural Extension and Communication Research, Ethiopian Institute of Agricultural Research (EIAR), Pawe Agricultural \\ Research Center, Pawe, Ethiopia
}

Email address:

takeleatnafu@gmail.com(T. A. Delele)

${ }^{*}$ Corresponding author

\section{To cite this article:}

Takele Atnafu Delele, Dirshaye Hailu Gebre, Talefe Ayele Zenebe. Roles of Community-Based Seed System to Mitigate Seed Shortage Problem Under Metekel Zone, Western Ethiopia. American Journal of Agriculture and Forestry. Vol. 9, No. 5, 2021, pp. $276-282$.

doi: 10.11648/j.ajaf.20210905.11

Received: August 8, 2021; Accepted: August 20, 2021; Published: September 10, 2021

\begin{abstract}
Seed is one of the major agricultural inputs to enhance agricultural production and productivity. Formal and informal seed systems are the main seed sources for producers. Majority $(90 \%)$ of seed demand has been covered through informal seed system. The main objectives of community-based seed system are to solve seed shortage problems, establish strong linkage among stakeholders and promoting new agricultural technologies rapidly to a wider geographical coverage. The activity was done in Metekel zone districts accordingly for the last four consecutive years. Soybean, sesame, wheat, fingure millet and rice were the priority crops included under community-based seed system. The system plays an indispensable role to reduce the problem of seed shortage in Benishangul Gumuz region in general and in Metekel zone in particular due to absence of seed enterprises. Community-based seed multiplication is also served as a strategic approach to promote the newly released crop varieties to address the wider areas of the communities rapidly. Results of community-based multiplication revealed that $1,160.889$ tons of certified seeds were produced from 709.05 hectares of land in the four consecutive years. The produced seeds highly reduced seed shortage problem in the study area and across the country. Pawe agricultural research center distributed 37.354 ton basic and pre-basic seeds for 506 seed producers with technical trainings and other full packages and the center has a lion share under this system. The system is significantly increased the income of seed producer farmers and highly perceived as a business. The government of Benishangul Gumuz has to give special attention for the establishment of seed enterprise since community-based seed system cannot be a permanent solution for securing seeds across the region.
\end{abstract}

Keywords: Community-based Seed System, Metekel, PARC, Seed

\section{Introduction}

Seed is the major input to ensure productivity, food and nutrition security [1]. Seed is one the key inputs in the overall journey of agricultural production system to improve crop production and productivity [2]. Farmers are using local poor quality seeds due to lack of awareness and knowledge regarding improved seeds and inaccessibility of improved seeds for farmers which causes low productivity. Application of quality seeds is one of the main elements to increase agricultural production in any farming system [3]. In developing and emerging economies including Ethiopia, seed sector development is a complex issue. A strong seed sector can contribute to a country's economic development, when it adopts vibrant, pluralistic, and market-oriented approaches [4]. Availability of improved seed is one of the most important inputs for producers to enhance productivity of agriculture in Ethiopia [5]. The contribution of seed is indispensable when it existing based on demanded quantity and quality to the users at the right time with an affordable price [6].

To ensure farmers' benefit from the genetic gain of crop improvement program, the newly released crop varieties need to be multiplied and made available rapidly to producers. Seed production is a significant factor of a functional seed system and is expected to produce sufficient quantity of seed with adequate quality within the national agreed rules, regulations and standards [7]. Formal and informal seed 
systems are the two broad types of the Ethiopian seed system. The two systems are operating simultaneously in the country and difficult to demarcate between them. However, the majority of the seeds delivered to the seed market are through the informal seed system. The formal seed system cannot satisfy the existing diversified and huge seed demand for the users. Ethiopian farmers particularly smallholder producers are engaged on multiple kinds of seed systems to secure their seed demands in the required quantity and quality and to market their produce [8].

Farmers have organized in to groups for establishing community-based seed system as an informal arrangement and producing and exchanging or selling quality seed through this system. Local and improved seeds can be included under this system. Informal seed system accounted $90 \%$ of the seed demands for smallholder farmers in Ethiopia. This system is easily accessible, affordable and more guaranteed for smallholder farmers. Remote locations that are far from the formal seed markets have been addressed through community-based seed system and it should be promoted as an effective approach for enhancing access to improved seeds to farmers. Under the formal seed system, public and private companies are engaged and produce and commercially sell seed under formal rules and regulations [9]. Seed systems in
Metekel zone were observed to be complex and Pawe agriculture research center plays a vital role. Absence of government supported and private seed enterprises, poor rural infrastructure and distribution mechanism in the region have been the production bottle necks of producers in Metekel zone [8]. Although shortage of improved seed is a great problem across the country, the problem is more magnifying in Metekel zone and the region due to absence of any seed enterprise in the area. Pawe agricultural research center already established a system of community-based seed multiplication with the collaboration of different stakeholders as a strategic solution for seed shortage problem and to deliver the newly released crop varieties for a large-segment of the community rapidly. The ultimate objective of implementing community-based seed multiplication in the study area was to mitigate a big problem of seed shortage in Metekel zone and the region since there is no any seed enterprise in the area. Currently, community-based seed system is the preferred strategic solution in the area regarding ensuring seed demand of both smallholder and commercial farmers. This informal seed system also can contribute the strengthening of stake holder linkage and facilitates to take a common action in the overall processes of improved seed multiplication and dissemination.

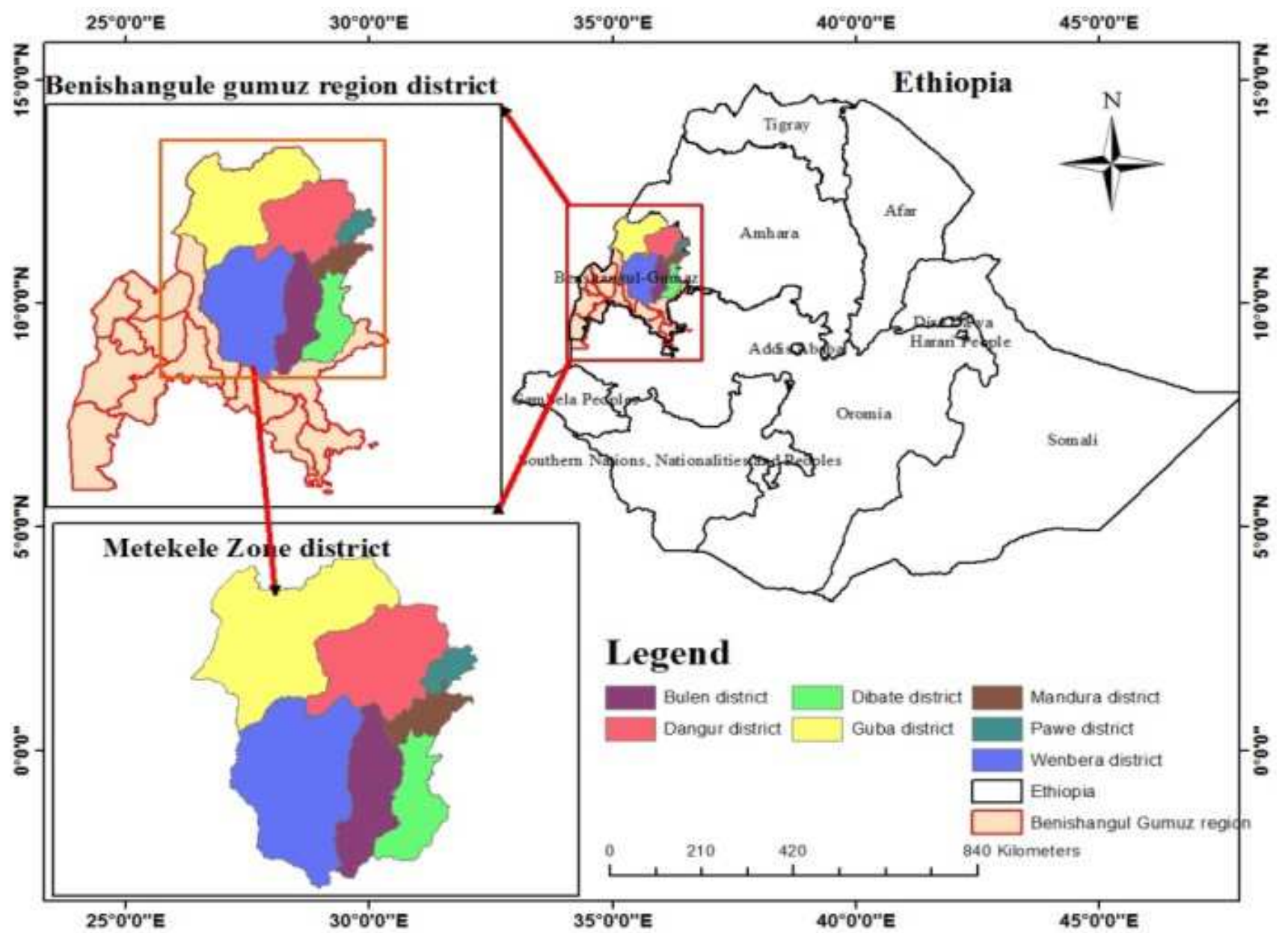

Figure 1. Map of the study area (Metekel zone). 


\section{Materials and Methods}

\subsection{Description of the Study Area}

Metekel is one of the three administrative zones of Benishangul Gumuz Regional State located in Western Ethiopia. It has borderlines with Awe zone in the East, Western Gondar in the North, North Sudan in the West and Kamashi zone in the South. It has 7 districts and three agro ecologies i.e., Dega, Kola and Woynadega. Metekel has untapped potential regarding agricultural production in all (Pawe, Dangur, Mandura, Guba, Debate, Bullen and Wombera) districts that is why many commercial farmers engaging in different crop production. Smallholder farmers follow mixed farming system both crop production and livestock raring. The area receives an average annual rainfall and temperature ranges from 600 to $1540 \mathrm{~mm} /$ year and 12 to $41^{\circ} \mathrm{C}$ respectively. The altitude ranges from 580 to 2730 m.a.s.l and selected crops have been multiplied in all districts of Metekel zone based on the suitability of agro ecologies for each crop varieties accordingly. It has a total population of 470,684 off which 233,040 is males and 237,644 are females. More than $98 \%$ of the rural population is depend on agriculture and $95 \%$ of them are living in the rural areas. Maize, sorghum, soybean, sesame, finger millet, wheat and ground nut are the dominant crops producing in Metekel zone.

\subsection{Site and Famer Selection}

Community-based seed multiplication has been implemented under all Metekel zone districts based on the suitability of the agro ecology of each crop varieties. Sites were selected carefully with farmers, development agents and with close guides of community-based seed multiplication monitoring and evaluation team. The sites selected by taking into account clustering approach for easy of monitoring and evaluation by stakeholders for its success. Community-based seed multiplication participant farmers were selected based on their willingness and performance to produce seeds with strict following of seed multiplication rules and standards. Special attention was given during selection of seed producer farmers to reduce failures of certified seeds. Communitybased seed multiplication monitoring and evaluation team evaluated the selected cluster sites and seed growers from different perspectives. After site and farmer selection, appropriate trainings were provided to seed growers, development agents, experts and other stakeholders regarding certified seed production and marketing by Pawe agricultural research center. Basic and pre-basic seeds of different crop varieties were provided to seed producers by PARC based on the suitability of the agro ecologies.

\subsection{Planting Materials}

Soybean (Ethio-Yugoslavia \& Gishama), rice (Pawe 1 \& Nerica-3), wheat (Danda'a \& Alidoro), sesame (Abasena \& dangur) and Fingure millet (Dibatsi \& Baruda) were the commodities used for community-based seed multiplication. All crops were secured from Pawe agricultural research center except wheat which came from Kulumisa agricultural research center.

\subsection{Data Collection}

Grain yield, germination, purity and farmers feedback were collected through data collection sheets. Quantity of certified seed sold for production, selling price and income received from each seed grower also collected accordingly.

\subsection{Economic Evaluation}

Simple financial analysis conducted to estimate the net benefit received from sale of certified seeds as compared to the grain yield. This was done by taking the selling price of certified seed and other grain non-certified yield with a specified market price.

\subsection{Data Analysis}

The collected data was analyzed through descriptive statistics by using Excel sheet and SPSS software package.

\section{Results and Discussion}

\subsection{Seed Systems in Metekel Zone, Benishangul Gumuz}

The seed systems of Metekel and the region depend on PARC and CBSM besides to the formal seed system. Pawe agricultural research center has provided basic and pre-basic seeds and technical trainings with full packages for seed growers. Development agents, experts and other stakeholders also received technical trainings from PARC. Communitybased seed system plays a crucial role to enhance rate of the newly released technology adoption to a wider geographical coverage and many technology users. PARC has a lion share in the overall processes of community-based seed multiplication to reduce the problem of seed shortage besides to the given mandates.

Community-based seed multiplication is a multidisciplinary and multi stakeholder task which needs collaboration and integration to meet its objectives successfully. The ultimate objective of this system is to solve seed shortage problem for smallholder and commercial farmers in Metekel zone and the region focusing on priority crops like soybean, rice, sesame, wheat and others. Besides CBSM also plays an indispensable role for promoting the newly released different crop varieties rapidly to address a wider section of the community. This system has its own monitoring and evaluation team which are organized from different disciplines from the research center and experts at different levels. The team supervises and follows seed producer farmers and their sites starting from site selection up to the seed certification and final distribution to the users for production. The monitoring and evaluation team performs the basic inspection process by three rounds besides to site 
selection. First round inspection has been conducted at vegetative and flowering stages of the multiplied seed and maturity stage for $2^{\text {nd }}$ round inspection. The $3^{\text {rd }}$ round inspection has been conducted at the post-harvest handling techniques until the seed has been certified and the team carefully follows each stage to ensure quality seed. Community-based seed system is served as a strategic linkage with different stakeholders and to take a common action together with PARC to solve immediate and long-term problems of producers. Since Metekel zone has untapped potential for agricultural production particularly on soybean, sesame, ground nut and others, many commercial farmers are involved in the area. These commercial farmers need large quantity of improved certified seed for their large-scale production. Commercial farmers strongly linked to PARC to get the required seed and other technical supports. Majority of seed request solved through the system of communitybased seed system since there is neither government nor private seed enterprise in the region at all. PARC plays a central role to link seed producer farmers with commercial farmers to smoothen the path way of seed marketing and this creates a good opportunities for both actors to ensure sustainable production.

\subsection{Capacity Development}

PARC has been provided technical trainings on the selected commodities to seed producers and experts. Each participant farmer took the trainings from land preparation, production and post-harvest handling techniques of the multiplied seed with full packages. Because quality seed production starts from site selection to final post-harvest handling systems until the produced seed has been certified and distributed to the end users. As the results depicted in Figure 2, 725 farmers and 276 experts took the training of community-based seed system in the four consecutive years.

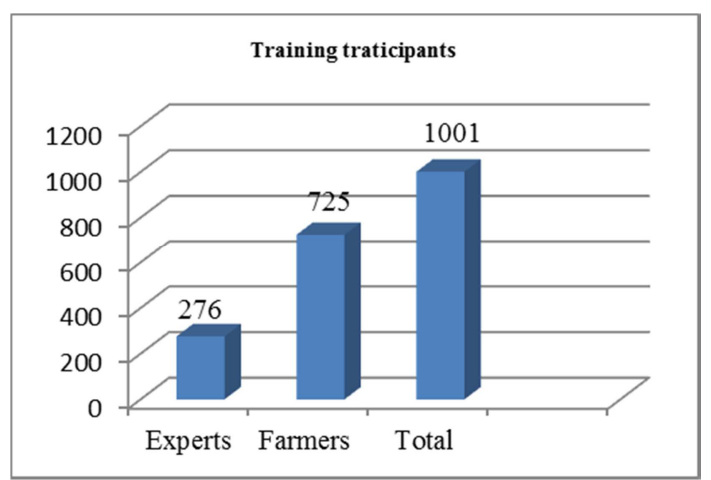

Figure 2. Capacity training participants.

As the results indicated in Table 1, a total volume of $1,160.889$ tons certified seeds were produced from 709.05 hectares of land by distributing 37.354 tons basic and prebasic seeds in the four consecutive production years. Soybean, rice, wheat, sesame and finger millet were the priority crops included under CBSM from 2016/17 to 2019/20 cropping season. This indicates that the need of CBSM system particularly in places like Metekel zone and the region is unquestionable. The findings of Croft, M. M. et al. also showed that the informal seed system potentially reduced seed shortage problem particularly for smallholder farmers and recommended to be strengthened [10]. Similarly, Sperling, L. et al. confirmed that the formal seed system cannot cover the seed demand for producers that is why the informal seed system has a lion share to answer the seed request of producers [11]. Ethio-Yugoslavia and Gishama from soybean, Pawe $1 \&$ Nerica-3 from rice, Alidoro \& Danda'a from wheat, Abasena \& Dangur from sesame and Dibatsi \& Baruda from Fingure millet were the varieties included under this informal seed system.

Table 1. Quantity of seeds produced (ton) from 2016/17-2019/20 cropping season.

\begin{tabular}{lllll}
\hline Crops & Variety & Seed distributed (ton) & Land covered (ha) & Seed produced (ton) \\
\hline Soybean & Ethio-Yugoslavia \& Gishama & 17.736 & 280.70 & 378.964 \\
Rice & Pawe 1 \& Nerica-3 & 5.982 & 83.55 & 222.625 \\
Wheat & Danda'a \& Alidoro & 9.900 & 84.00 & 242.975 \\
Sesame & Abasena \& Dangur & 2.814 & 184.30 & 80.300 \\
Fingure millet & Dibatsi \& Baruda & 0.924 & 76.50 & 236.025 \\
Total & & 37.354 & 709.05 & $1,160.889$ \\
\hline
\end{tabular}

Source: Own computation.

The results depicted in Table 2 showed that a total of 506 (382 males \& 124 females) direct seed producer farmers were engaged under this system of CBSM in Metekel zone districts. Totally, these participants produced $1,160.889$ tons certified seed as explained above starting from 2016/172019/20 cropping season and this solved seed shortage problem of many smallholder and commercial farmers in the area. The finding agrees with Nateebwa, M. et al. who confirmed that community-based seed multiplication is a successful approach to ensure access to quality seed to producers and agricultural research institutes and development actors commonly use to meet the seed demands [4]. The finding by Sisay, D. T. et al. found that informal seed system significantly contributed regarding seed security for producers and policy makers and development practitioners recognize the system to solve shortage of seed [9]. The result is similar to Welu who found that the informal seed system play an indispensible role to ensure seeds widely for a large-segment of the community [12]. Community-based seed system is a major means to ensure food security and $80 \%$ of the seed source secured from this informal seed system [13]. 
Table 2. Quantity of seed produced and participant farmers/2016/17-2019/20 cropping season.

\begin{tabular}{|c|c|c|c|c|c|c|}
\hline \multirow[b]{2}{*}{ Year } & \multirow[b]{2}{*}{ Seed distributed (ton) } & \multirow[b]{2}{*}{ Land covered (ha) } & \multirow[b]{2}{*}{ Seed produced (ton) } & \multicolumn{2}{|c|}{ Participants farmers } & \multirow[b]{2}{*}{ Total } \\
\hline & & & & Male & Female & \\
\hline $2016 / 17$ & 5.339 & 164.95 & 238.775 & 93 & 12 & 106 \\
\hline $2017 / 18$ & 13.867 & 307.00 & 579.125 & 146 & 34 & 180 \\
\hline 2018/19 & 12.733 & 178.60 & 207.439 & 111 & 71 & 182 \\
\hline $2019 / 20$ & 5.415 & 58.50 & 135.550 & 32 & 7 & 39 \\
\hline Total & 37.354 & 709.05 & 1160.889 & 382 & 124 & 506 \\
\hline
\end{tabular}

Source: Own computation.

During 2016/17 cropping season, 238.775 ton certified seeds were produced by 106 seed growers. Similarly, 5.339 ton basic and pre-basic seeds were distributed from Pawe agricultural research center to seed producers and 164.95 hectares of land were covered by soybean, rice, wheat, sesame and Fingure millet crops. As the results indicated in Table 3, 579.125 ton certified seeds were produced from 307.00 hectares of land by distributing 13.867 ton basic and pre-basic seeds to 180 seed producers in $2017 / 18$ cropping season. Similarly, 207.439 and 135.550 ton certified seeds were produced by 182 and 39 seed growers in 2018/19 and 2019/20 production season respectively. At the same time, 12.733 and 5.415 ton basic and pre-basic seeds were distributed and 178.60 and 58.50 hectares of land were covered under CBSM. Overall, community-based seed system is the major source of seeds for most of smallholder and commercial farmers and main source of income for seed growers.

Table 3. Seed production by crop type under each cropping season.

\begin{tabular}{|c|c|c|c|c|c|c|}
\hline Crop & Seed (ton) & Land (ha) & Yield (ton) & Male & Female & Total \\
\hline \multicolumn{4}{|c|}{ 2016/17 Cropping Season } & \multicolumn{3}{|c|}{ Participant Farmers } \\
\hline Soybean & 2.288 & 32.45 & 55.000 & 14 & 2 & 16 \\
\hline Rice & 1.545 & 21.75 & 62.500 & 15 & 0 & 15 \\
\hline Wheat & 0.700 & 10.00 & 39.100 & 13 & 7 & 20 \\
\hline Sesame & 0.620 & 77.50 & 31.650 & 26 & 2 & 29 \\
\hline Fingure millet & 0.186 & 23.25 & 50.525 & 25 & 1 & 26 \\
\hline Total & 5.339 & 164.95 & 238.775 & 93 & 12 & 106 \\
\hline Soybean & 8.250 & 137.5 & 233.75 & 18 & 0 & 18 \\
\hline Rice & 1.669 & 22.25 & 77.875 & 22 & 0 & 22 \\
\hline Wheat & 1.200 & 10.00 & 40.000 & 14 & 6 & 20 \\
\hline Sesame & 2.011 & 84.00 & 42.000 & 45 & 21 & 66 \\
\hline Fingure millet & 0.738 & 53.25 & 185.500 & 47 & 7 & 54 \\
\hline Total & 13.867 & 307.00 & 579.125 & 146 & 34 & 180 \\
\hline \multicolumn{4}{|c|}{ 2018/19 Cropping Season } & \multicolumn{3}{|c|}{ Participant Farmers } \\
\hline Wheat & 5.000 & 40.00 & 98.275 & 23 & 15 & 38 \\
\hline Sesame & 0.183 & 22.80 & 6.650 & 23 & 28 & 51 \\
\hline Total & 12.733 & 178.60 & 207.439 & 111 & 71 & 182 \\
\hline \multicolumn{4}{|c|}{ 2019/20 Cropping Season } & \multicolumn{3}{|c|}{ Participant Farmers } \\
\hline Soybean & 0.648 & 9.25 & 4.250 & 8 & 0 & 8 \\
\hline Rice & 1.768 & 25.25 & 65.700 & 10 & 0 & 10 \\
\hline Wheat & 3.000 & 24.00 & 65.600 & 14 & 7 & 21 \\
\hline Total & 5.415 & 58.50 & 135.550 & 32 & 7 & 39 \\
\hline
\end{tabular}

Source: own computation.

\subsection{Financial Analysis}

The produced certified seeds sold to both smallholder and commercial farmers with better price. Seed producer farmers received good return from their certified seeds since the selling price of the certified seed is $20 \%$ more than the existing market price within that particular marketing season. The results depicted in Table 4 showed that seed growers sold their sesame with the price of 7,900.00-ETB ton $^{-1}$ more as compared to the grain yield in 2019 marketing year. Soybean and wheat seed producers sold their seed produce with the price increment of 6916.60 and 4000.00 -ETB ton $^{-1}$ respectively. Similarly, seed producers received 3716.70 and $2940.00 \mathrm{ETB}^{-1}$ ton $^{-1}$ more price as compared to the grain yield with the specified market price from fingure millet and rice seeds. This implies that farmers who are involved in community-based seed multiplication can receive more than $20 \%$ price increment from their certified seeds as compared to grain yield and that is why this system has been perceived as a business beyond seed security by most of the beneficiaries. The finding is in line with Tebeka, Y. A. et al. who found that community-based seed multiplication is a 
profitable enterprise and increases farmers' income besides securing seed demands particularly in the remote farmers [14]. The investigation conducted by Sapkota et al. also indicates that participation of farmers in seed production positively increases farmers' income [15]. Besides couple purpose of increasing farmers' income and mitigating seed shortage problems, this system well strengthening stakeholders' and marketing linkages among actors. Community-based seed system served as a strategic approach to promote new agricultural technologies rapidly to a largesegment of the community.

Table 4. Price difference analysis of grain and certified seeds of seed growers/2019/20.

\begin{tabular}{llll}
\hline Crops & Grain sale price ETB ton & Difference ETB ton $^{-1}$ & Seed sale price ETB ton $^{-1}$ \\
\hline Soybean & 11250.10 & 18166.70 & 6916.60 \\
Rice & 14700.00 & 17640.00 & 2940.00 \\
Wheat & 16000.00 & 20000.00 & 4000.00 \\
Sesame & 39500.00 & 47400.00 & 7900.00 \\
Fingure millet & 18583.30 & 22300.00 & 3716.70 \\
\hline
\end{tabular}

$\mathrm{ETB}=$ Ethiopian Birr

Source: Own computation from data, 2019.

\subsection{Feedbacks}

Seed producers highly perceived community-based seed multiplication as a powerful tool to increase the incomes of smallholder producers and a strategic solution for reducing the problem of seed shortage better than the formal seed system. They perceived as a business beyond seed security and need to continue with this system. Linkages among stakeholders particularly research-farmer-investor strongly connected due to seed production and marketing.

\section{Conclusion and Recommendations}

Community-based seed system plays an indispensable role to reduce the problems of seed shortage across all over Metekel zone and the region as far as each stakeholder performs their tasks properly. Community-based seed multiplication is a strategic linkage among stakeholders regarding seed production and marketing. The system also served as a strategic approach to promote the newly released different crop technologies rapidly to a large-segment of the community besides ensuring seed security. This system now is considered as a business besides securing seeds to smallholder and commercial farmers in Metekel and the region by most of the producers. Therefore, communitybased seed system has to be continued and strengthen until the region establishing seed enterprises. The government of Benishangul Gumuz has to give special attention for the establishment of either governmental or private seed enterprises since community-based seed system cannot be served as a permanent solution for seed security.

\section{References}

[1] McGuire, S. and L. Sperling, Seed systems smallholder farmers use. Food Security, 2016.8 (1): p. 179-195.

[2] Atilaw, A., et al., Early generation seed production and supply in Ethiopia: Status, challenges and opportunities. Ethiopian Journal of Agricultural Sciences, 2016. 27 (1): p. 99-119.
[3] Sabry, G., The importance of using high quality seeds in agricultural systems. Agricultural Research and Technology: Open Access Journal, 2018. 15 (4).

[4] Nateebwa, M., J. Okiror, and M. M. Najjingo, Effectiveness of community based seed multiplication in enhancing farmers' knowledge and access to improved bean seeds in western Uganda. African Crop Science Journal, 2017. 25 (3): p. 321332 .

[5] Kifle, T. and A. Atilaw, Constraints to private seed sector development in Ethiopia: A case study. African Journal of Agricultural Research, 2018. 13 (48): p. 2748-2756.

[6] Tarekegn, K. and M. Mogiso, Assessment of improved crop seed utilization status in selected districts of Southwestern Ethiopia. Cogent Food \& Agriculture, 2020. 6 (1): p. 1816252.

[7] Atilaw, A. and L. Korbu, Recent development in seed systems of Ethiopia. Improving farmers' access to seed, 2011: p. 1330 .

[8] Assaye, A., et al., Assessment of seed systems in North Western Ethiopia; with special emphasis on community based seed multiplication scheme. World Scientific News, 2015. 12: p. 55-65.

[9] Sisay, D. T., F. J. Verhees, and H. C. van Trijp, Seed producer cooperatives in the Ethiopian seed sector and their role in seed supply improvement: A review. Journal of crop improvement, 2017. 31 (3): p. 323-355.

[10] Croft, M. M., et al., Formal and informal seed systems in Kenya: Supporting indigenous vegetable seed quality. The Journal of Development Studies, 2018. 54 (4): p. 758-775.

[11] Sperling, L., et al., Informal seed traders: the backbone of seed business and African smallholder seed supply. Sustainability, 2020. 12 (17): p. 7074.

[12] Welu, G., Challenges and opportunities of seed multiplication in Eastern Tigray Ethiopia. Journal of Biology, Agriculture and Healthcare, 2015. 5 (3): p. 42-53.

[13] Gauchan, D. and R. B. Shrestha, Community Based Seed Systems for Agrobiodiversity and Resilient Farming of Smallholder Agriculture in South Asia. Strengthening Seed Systems-Promoting Community Based Seed Systems for Biodiversity Conservation and Food \& Nutrition Security in South Asia, 2020: p. 29-53. 
[14] Tebeka, Y., et al., Economic performance of community based bean seed production and marketing in the central rift valley of Ethiopia. African Crop Science Journal, 2017. 25 (2): p. 189-205.
[15] Sapkota, M., et al., Determinants of maize seed income and adoption of foundation seed production: evidence from Palpa District of Nepal. Agriculture \& Food Security, 2017. 6 (1): p. $1-10$. 